\title{
Intramedullary endodermal cyst including glial tissues in the spinal cord
}

\author{
Yuichiro Ichihara $^{1}$ - Narihito Nagoshi ${ }^{1} \cdot$ Shuji Mikami $^{2}$ - Satoshi Suzuki ${ }^{1}$ Osahiko Tsuji ${ }^{1}$ - Ejiro Okada ${ }^{1}$ \\ Mitsuru Yagi ${ }^{1} \cdot$ Kota Watanabe $^{1} \cdot$ Nobuyuki Fujita $^{3} \cdot$ Masaya Nakamura $^{1} \cdot$ Morio Matsumoto $^{1}$
}

Received: 26 February 2020 / Revised: 19 April 2020 / Accepted: 21 April 2020

(C) International Spinal Cord Society 2020

\begin{abstract}
Introduction Spinal intramedullary endodermal cyst is a rare spinal cord tumour. In particular, an endodermal cyst that includes glial tissues is extremely rare. Herein, we present the case of an individual with a thoracic spinal cord intramedullary endodermal cyst, which includes glial tissues that achieved gross total resection by surgery.

Case presentation A 59-year-old man presented with a 10-month history of right thigh pain and numbness. Magnetic resonance imaging (MRI) revealed a well-marginated 15-mm cystic lesion at the T7-T8 level. We performed cystectomy and achieved gross total resection. Pathological findings revealed an endodermal cyst, with the presence of glial tissues. No recurrence of cysts was observed upon MRI 2 years after the surgery.

Discussion Endodermal cyst is defined by pathological findings of a cyst lined by columnar epithelium of presumed endodermal derivation. To date, only 104 reported cases of intramedullary endodermal cysts have been reported; our report was the third case that showed the presence of glial cells in the cyst during pathological examination. Intramedullary cysts are generally difficult to completely resect, with many recurrences. Although we achieved gross total resection, careful follow-up is necessary in the future.
\end{abstract}

\section{Introduction}

Endodermal cysts are rare lesions accounting for $0.7-1.3 \%$ of all spinal cord tumours. Approximately $90 \%$ of these tumours are located in the intradural extramedullary compartment, whereas the remaining $10 \%$ are in the intramedullary compartment [1]. In particular, an endodermal cyst including glial tissues is extremely rare. Herein, we present the case of an individual with a thoracic spinal cord intramedullary endodermal cyst with the presence of glial tissues that achieved gross total resection.

Narihito Nagoshi

nagoshi@2002.jukuin.keio.ac.jp

1 Department of Orthopaedic Surgery, Keio University School of Medicine, Tokyo, Japan

2 Division of Diagnostic Pathology, Keio University School of Medicine, Tokyo, Japan

3 Department of Orthopaedic Surgery, Fujita Health University, Aichi, Japan

\section{Case presentation}

A 59-year-old man presented with a 10-month history of right thigh pain and numbness. However, his medical history was unremarkable.

Physical examination revealed right thigh pain and numbness, with sensory disorder of the lower half of the body. He had exaggerated bilateral patellar tendon and Achilles tendon reflexes and positive bilateral Babinski reflexes. However, his lower limb strength and bowel and bladder functions were normal. The Japan Orthopaedic Association (JOA) score is a scoring system for thoracic myelopathy that evaluates the motor and sensory functions of the lower extremity and bladder function, and has a total of 11 points. In this case, the JOA was 7.5/11.

$\mathrm{X}$-ray and computed tomography revealed no structural anomalies. MRI revealed the presence of a well-marginated 15-mm cystic lesion with hypointensity on T1-weighted image, hyperintensity on T2-weighted image and a solid component at the T7-T8 level. The wall of the cyst was slightly enhanced on contrast T1-weighted image (Fig. 1). Ependymal cysts, dermoid cysts, epidermoid cysts and endodermal cysts were suspected as intramedullary cystic 


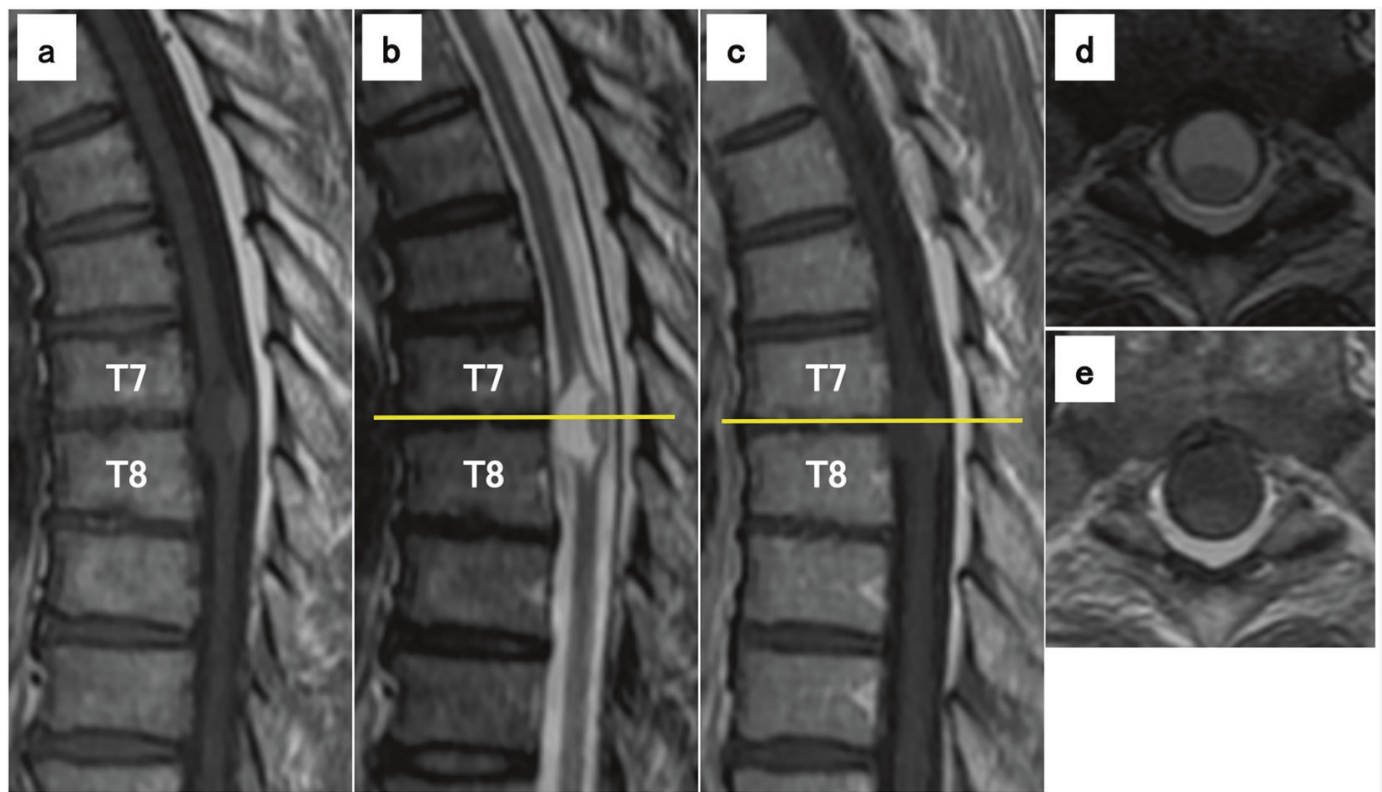

Fig. 1 Preoperative magnetic resonance imaging. a Sagittal T1; b sagittal T2; c sagittal Gd; d axial T2; e axial Gd.

Fig. 2 Intraoperative findings. a Breaking of the posterior median sulcus; $\mathbf{b}$ incision of the capsule of the cyst; $\mathbf{c}$ removal of the capsule; $\mathbf{d}$ achievement of gross total resection.
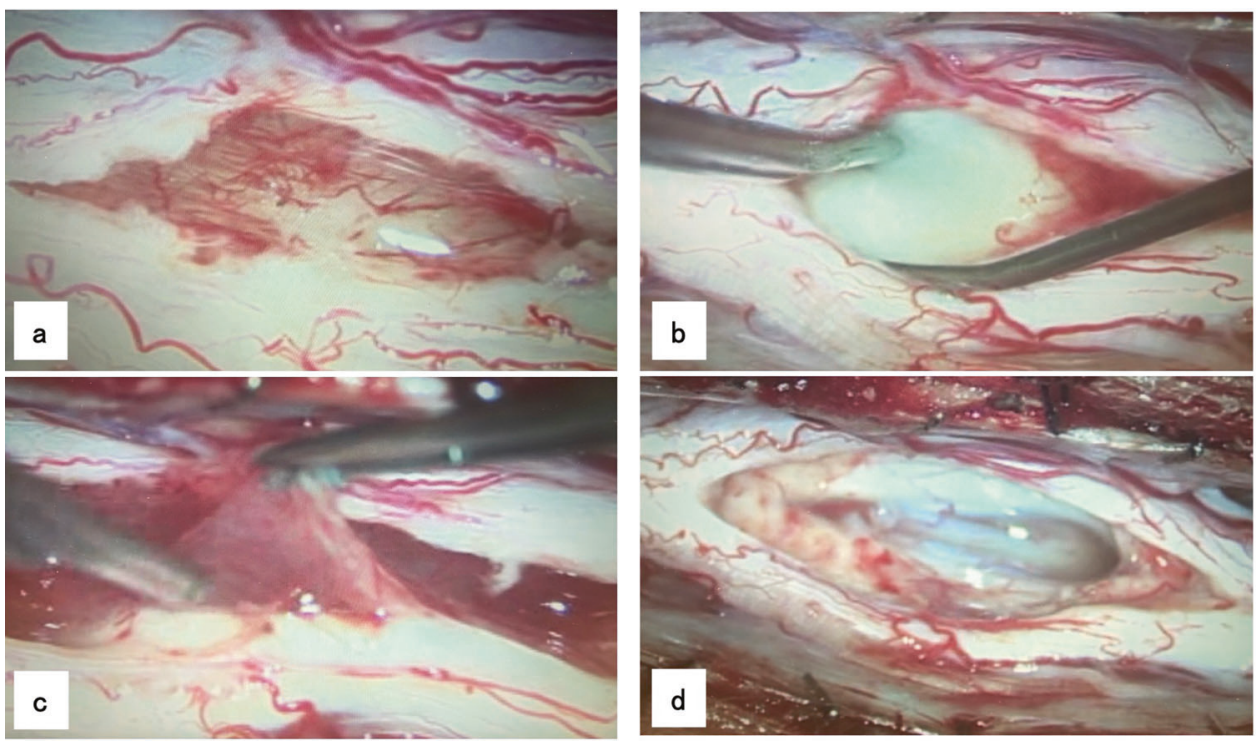

lesions; however, the image could not provide a clear distinction. Considering the diagnostic findings, we performed cystectomy.

First, we performed laminectomy from T7 to T9 and observed the interior part of the dura using ultrasonography to confirm the localisation of the cyst. Subsequently, we incised the dura and approached the cyst by breaking the posterior median sulcus and exposed the cyst capsule using an intraoperative microscope. On incising the capsule, we observed the accumulation of a white turbid liquid. We removed this liquid and excised the capsule from the normal spinal cord whilst closely monitoring the motor evoked potentials. We performed this procedure with utmost care because the capsule adhered to the normal spinal cord, achieving gross total resection of the cyst (Fig. 2).

In the cyst, we observed lining rows of ciliated columnar epithelial cells that were positive for pan-cytokeratin staining, an epithelial marker. The individual was then diagnosed with an endodermal cyst. Glial fibrillary acidic protein (GFAP)- and S100-positive glial cells were also observed in the subepithelial connective tissue (Fig. 3). According to Wilkins and Odom classification, the cyst was a type $\mathrm{C}$ cyst, which includes glial tissues [2].

His right thigh pain has improved since 2 years, with a JOA score of 7.5/11. Furthermore, MRI revealed no recurrence of the cysts (Fig. 4). 
Fig. 3 Pathological findings.

a The cyst is lined with ciliated columnar epithelial cells (arrows), H\&E; b positive for pan-cytokeratin staining; c positive for GFAP; $\mathbf{d}$ positive for $\mathrm{S} 100$.

Fig. 4 Magnetic resonance imaging 2 years after the surgery. a sagittal $\mathrm{T} 1$; b sagittal T2; c sagittal Gd; d axial T2; e axial $\mathrm{Gd}$.
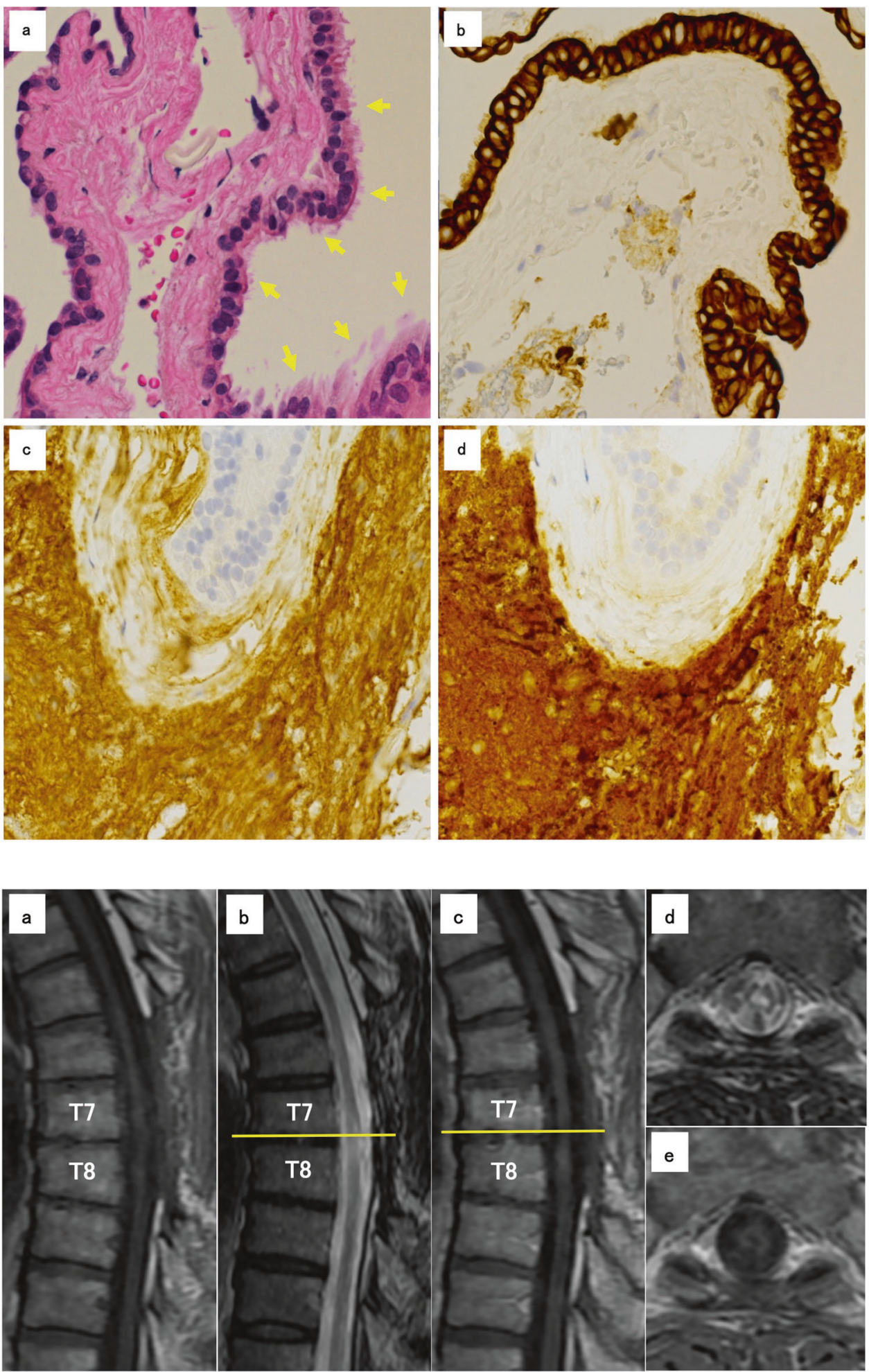

\section{Discussion}

The precise pathogenesis of endodermal cysts still remains unclear. One of the most widely accepted aetiologies of cysts is the failure of separation of the ectoderm (notochord) and the endoderm (foregut) during the third week of human embryogenesis [3]. The frequency with which it occurs in males and females is $2: 1$ [4]. Endodermal cyst diagnosis is based on pathological findings. Endodermal cysts are defined as cysts lined by columnar epithelium of presumed 
Table 1 Summary of intramedullary endodermal cysts described in the literature.

\begin{tabular}{|c|c|c|c|c|c|c|c|}
\hline Year & Author & Age & Sex & $\begin{array}{l}\text { Cyst } \\
\text { location }\end{array}$ & Treatment & $\begin{array}{l}\text { Recurrence, re- } \\
\text { growth or refilling }\end{array}$ & $\mathrm{FU}$ (month) \\
\hline 1972 & Silvernail and Brown & 12 years & M & $\mathrm{C} 2-\mathrm{T} 2$ & $\begin{array}{l}\text { STR and } \\
\text { Shunting }\end{array}$ & No & 16 \\
\hline 1988 & Mizuno et al. & 6 years & M & $\mathrm{C} 2-5$ & Aspiration & Yes & 96 \\
\hline 1993 & Khandelwal et al. & 25 years & $\mathrm{M}$ & T9-10 & GTR & No & 3 \\
\hline 1996 & Rao et al. & 27 years & M & $\mathrm{C} 7$ & STR & No & 30 \\
\hline 1997 & Rivierez et al. & 46 years & $\mathrm{F}$ & L1-2 & Shunting & No & 6 \\
\hline 2001 & Lippman et al. & 68 years & $\mathrm{F}$ & T10-11 & STR & No & 1.5 \\
\hline 2001 & Reinders et al. & 3 years & $\mathrm{F}$ & T8-9 & STR & No & 2 \\
\hline 2001 & Sharma et al. & 24 years & $\mathrm{F}$ & L1-2 & STR & Yes & 60 \\
\hline \multirow[t]{2}{*}{2002} & \multirow[t]{2}{*}{ Kumar and Nayak } & 9 years & $\mathrm{F}$ & $\mathrm{C} 5-\mathrm{T} 1$ & STR & No & 6 \\
\hline & & 15 months & $\mathrm{M}$ & L2-4 & STR & No & 3 \\
\hline 2003 & \multirow{4}{*}{$\begin{array}{l}\text { Paolini et al. } \\
\text { de Oliveira et al. }\end{array}$} & 28 years & $\mathrm{F}$ & T8-9 & STR & No & 12 \\
\hline \multirow[t]{3}{*}{2005} & & 6 years & $\mathrm{M}$ & $\mathrm{C} 4-7$ & GTR & Yes & 96 \\
\hline & & 6 years & $\mathrm{F}$ & $\mathrm{C} 7-\mathrm{T} 1$ & GTR & No & 168 \\
\hline & & 21 days & $\mathrm{M}$ & $\mathrm{T} 10$ & GTR & No & 0.75 \\
\hline \multirow[t]{3}{*}{2005} & \multirow[t]{3}{*}{ Rotondo et al. } & 67 years & $\mathrm{F}$ & T10-11 & GTR & No & 3 \\
\hline & & 53 years & $\mathrm{F}$ & T12-L1 & GTR & No & 12 \\
\hline & & 61 years & $\mathrm{F}$ & T12-L1 & GTR & No & 6 \\
\hline \multirow[t]{2}{*}{2006} & \multirow[t]{2}{*}{ Menezes and Traynelis } & 6 years & $\mathrm{M}$ & $\mathrm{C} 2-3$ & STR & Yes & 216 \\
\hline & & 40 years & $\mathrm{M}$ & C6 & STR & Yes & 36 \\
\hline 2007 & Nagi et al. & 40 years & $\mathrm{F}$ & C3-4 & GTR & No & 3 \\
\hline 2008 & Cai et al. & 3 years & $\mathrm{F}$ & $\mathrm{C} 7-\mathrm{T} 1$ & GTR & No & 60 \\
\hline 2008 & Muzumdar et al & 12 years & $\mathrm{M}$ & $\mathrm{C} 2-3$ & GTR & No & 36 \\
\hline 2008 & Takahashi et al. & 8 years & $\mathrm{M}$ & T5 & Aspiration & Yes & 36 \\
\hline \multirow[t]{5}{*}{2008} & \multirow[t]{5}{*}{ Garg et al. } & 9 years & $\mathrm{F}$ & $\mathrm{T} 1$ & STR & Yes & 36 \\
\hline & & 10 years & $\mathrm{M}$ & T3-5 & STR & No & 12 \\
\hline & & 14 years & $\mathrm{M}$ & $\mathrm{C} 3$ & GTR & No & 84 \\
\hline & & 22 years & $\mathrm{F}$ & $\mathrm{C} 7-\mathrm{T} 2$ & STR & No & 36 \\
\hline & & 25 years & $\mathrm{M}$ & $\mathrm{C} 5-7$ & GTR & No & 2 \\
\hline 2009 & Yilmaz et al. & 17 years & $\mathrm{M}$ & T12-L1 & STR & No & 6 \\
\hline 2010 & Theret et al. & 30 days & $\mathrm{M}$ & C6-7 & STR & No & 24 \\
\hline 2011 & Balasubramaniam et al. & 2 years & $\mathrm{M}$ & T12-L1 & STR & No & 12 \\
\hline 2011 & Wakao et al. & 57 years & M & $\mathrm{T} 1-2$ & $\begin{array}{l}\text { STR and } \\
\text { Shunting }\end{array}$ & No & 12 \\
\hline \multirow[t]{13}{*}{2015} & \multirow[t]{13}{*}{ Tao et al. } & 10 years & $\mathrm{M}$ & C3-5 & GTR & No & 122 \\
\hline & & 25 years & $\mathrm{M}$ & L3 & GTR & No & 114 \\
\hline & & 53 years & $\mathrm{F}$ & $\mathrm{T} 11-12$ & GTR & No & 102 \\
\hline & & 43 years & $\mathrm{M}$ & C3-6 & STR & Yes & 93 \\
\hline & & 39 years & $\mathrm{M}$ & T5 & GTR & No & 84 \\
\hline & & 41 years & $\mathrm{F}$ & C3-4 & STR & Yes & 70 \\
\hline & & 47 years & $\mathrm{M}$ & $\mathrm{L} 1$ & STR & Yes & 65 \\
\hline & & 64 years & $\mathrm{M}$ & $\mathrm{T} 7$ & GTR & No & 54 \\
\hline & & 23 years & $\mathrm{M}$ & C3-4 & GTR & No & 50 \\
\hline & & 13 years & $\mathrm{F}$ & $\mathrm{T} 1-2$ & STR & Yes & 42 \\
\hline & & 15 years & $\mathrm{F}$ & $\mathrm{C} 6-\mathrm{T} 1$ & GTR & No & 34 \\
\hline & & 53 years & $\mathrm{F}$ & $\mathrm{T} 10-12$ & GTR & No & 23 \\
\hline & & 51 years & $\mathrm{F}$ & $\mathrm{C} 5$ & STR & No & 11 \\
\hline 2016 & Bruzek et al. & 47 years & $\mathrm{M}$ & $\mathrm{C} 2-\mathrm{C} 7$ & GTR & No & 3 \\
\hline 2017 & Aiyappan et al. & 34 years & $\mathrm{M}$ & T12-L1 & STR & No & 24 \\
\hline 2017 & Joshi et al. & 8 years & $\mathrm{M}$ & T3-6 & GTR & No & 3 \\
\hline 2019 & Chen et al. & 46 years & $\mathrm{F}$ & $\mathrm{C} 0-1$ & STR & No & 3 \\
\hline
\end{tabular}

endodermal derivation [5]. Cysts with these features have been variably designated as neuroenteric, enterogenous or bronchogenic. The term 'endodermal' encompasses the lesions occurring intracranially and throughout the spinal axis, as defined by the Armed Forces Institute of Pathology (AFIP) in 1993 [6]. Wilkins and Odom have pathologically 
classified endodermal cysts into three types. Type A cysts compose of columnar or cuboidal cells atop a basement membrane, without other elements. Type B cysts include all of the features of type A and additional tissue that may include bone, cartilage, lymphatic tissue, fat, or glandular components, such as respiratory or intestinal organs. Type $\mathrm{C}$ cysts have type A features associated with ependymal or glial tissues [2,4]. In the present case, the cyst was lined with ciliated columnar epithelial cells and was positive for pan-cytokeratin staining, indicating the typical diagnosis of an endodermal cyst. Furthermore, this case showed the presence of glial cells that were positive for GFAP and S100 in the subepithelial connective tissue, suggesting the cyst to be a type $\mathrm{C}$ cyst. Endodermal cysts are typically negative for GFAP; however, some studies have reported that cysts may be positive for GFAP in some intramedullary cases $[2,4,7]$; our case is consistent with these reports. To the best of our knowledge, our case is the third case of type $\mathrm{C}$ cyst of intramedullary endodermal cyst $[2,7]$.

In the present case, MRI revealed the presence of a wellmarginated cystic lesion with hypointensity on T1-weighted image, hyperintensity on T2-weighted image and slightly enhanced wall on contrast T1-weighted image. These findings are typical of various cystic lesions, including endodermal cysts. Therefore, differentiating our individual's cyst from other cystic lesions based on MRI findings alone was difficult. Previous MRI findings of endodermal cysts, such as being well-marginated, hypointense on T1weighted image, hyperintense on T2-weighted image and slightly enhanced wall on contrast T1-weighted image, are similar to those of our case $[8,9]$. However, a characteristic finding of endodermal cysts is that the content fluid comprises mucin and protein components; therefore, various signal intensities can be exhibited depending on their properties, viscosity, and concentration $[8,9]$.

Ependymal cysts can be differentially diagnosed as spinal intramedullary cystic lesions; however, as described above, it is difficult to diagnose based on the image findings alone. Ependymal cysts are defined as appropriate for benign, intraparenchymal and often paraventricular cysts in which the lining lacks cilia and shows the presence of S100 protein and occasionally GFAP-reactive cells [5], which distinguishes it from endodermal cysts.

Endodermal cysts are benign lesions; however, the primary pathogenic mechanism of intramedullary lesions is chronic spinal cord compression. Therefore, surgery is the first treatment choice for neural decompression and prevention of cystic refilling [10]. In addition to resection, cyst aspiration and cyst-subarachnoid shunting have been performed. However, aspiration cannot yield a pathological diagnosis and results in a high refilling rate $[1,10-15]$. The spillage of cyst contents into the subarachnoid space caused
Table 2 The surgical method, postoperative recurrence, and observation period of 49 previous cases.

\begin{tabular}{llll}
\hline Method & Cases & $\begin{array}{l}\text { Recurrence, re-growth } \\
\text { or refilling }\end{array}$ & Observation period \\
\hline GTR & 22 & $1(4.5 \%)$ & 48.3 months \\
STR & 22 & $8(36.4 \%)$ & 36.4 months \\
Aspiration & 2 & $2(100 \%)$ & 66.0 months \\
Shunting & 3 & $0(0.0 \%)$ & 11.3 months \\
\hline
\end{tabular}

GTR gross total resection, STR subtotal resection.

during shunting may cause meningitis $[1,15]$. Therefore, we performed resection to avoid these risks.

Our extensive research revealed that only 104 cases of intramedullary endodermal cysts have been reported. Of these, 49 confirmed the surgical method, postoperative recurrence, re-growth or refilling and observation period (Table 1). In addition, 22 cases achieved gross total resection, whereas another 22 cases achieved subtotal resection because the cyst was adhered to the normal spinal cord. Two cases underwent aspiration and three cases underwent shunting. We found one case of recurrence $(4.5 \%)$ after gross total resection and eight cases of re-growths (36.4\%) after subtotal resection (Table 2). Therefore, achieving gross total resection reduces the risk of recurrence, re-growth or refilling and is an effective treatment for cysts.

In the present case, we carefully removed the capsule of the cyst from the normal spinal cord. No recurrence has been observed 2 years after the achievement of gross total resection. Previous studies have reported that the possibility of recurrence in this case may not be high; however, reports on the long-term outcomes of intramedullary endodermal cysts achieving gross total resection are still few; thus, careful follow-up is required.

\section{Compliance with ethical standards}

Conflict of interest The authors declare that they have no conflict of interest.

Publisher's note Springer Nature remains neutral with regard to jurisdictional claims in published maps and institutional affiliations.

\section{References}

1. Fortuna A, Mercuri S. Intradural spinal cysts. Acta Neurochirurgica. 1983;68:289-314.

2. Wilkins RH, Odom GL. Spinal intradural cysts. In: Vinkin PJ, Bruyn GW, editors. Tumors of the spine and spinal cord, Part II. Handbook of clinical neurology. Vol 20. Amsterdam: North Holland Publishing; 1976. p 55-102.

3. Langman J. Medical embryology: human development - normal and abnormal. 2nd edn; Baltimore: Williams and Wilkins; 1969. 
4. Savage JJ, Casey JN, McNeill IT, Sherman JH. Neurenteric cysts of the spine. J Craniovert Jun Spine 2010;1:58-63.

5. Peter C, Bernd W. Tumor of the central nervous system. AFIP atlas of tumor pathology, series 4. Washington, DC: American Registry of Pathology; 2007.

6. Peter C, Bernd W. Tumor of the central nervous system. AFIP Atlas of Tumor Pathology, series 2. Washington, DC: American Registry of Pathology; 1994.

7. Lippman CR, Arginteanu M, Purohit D, Naidich TP, Camins MB. Intramedullary neurenteric cysts of the spine. J Neurosurg. 2001;94:305-9.

8. King NK, Joshi SM, Marino S, Ten JS, Ellamushi H. Dorsally located endodermal cyst: case report and review. Br J Neurosurg. 2009;23:318-20.

9. Yang T, Wu L, Fang J, Yang C, Deng X, Xu Y. Clinical presentation and surgical outcomes of intramedullary neurenteric cysts. J Neurosurg Spine. 2015;23:99-110.
10. Mizuno J, Fiandaca MS, Nishio S, O’Brien MS. Recurrent intramedullary enterogenous cyst of the cervical spinal cord. Childs Nerv Syst. 1988;4:47-9.

11. de Oliveira RS, Cinalli G, Roujeau T, Saint-Rose C, PierreKahn A, Zerah M. Neurenteric cysts in children: 16 consecutive cases and review of the literature. J Neurosurg. 2005;103: $512-23$.

12. Kumar R, Nayak SR. Unusual neuroenteric cysts: diagnosis and management. Pediatr Neurosurg. 2002;37:321-30.

13. Menezes AH, Traynelis VC. Spinal neurenteric cysts in the magnetic resonance imaging era. Neurosurgery. 2006;58:97-105.

14. Muzumdar D, Bhatt Y, Sheth J. Intramedullary cervical neurenteric cyst mimicking an adscess. Pediatr Neurosurg. 2008; 44:55-61.

15. Rotondo M, D’Avanzo R, Natale M, Pasqualetto L, Bocchetti A, Agozzino L, et al. Intramedullary neurenteric cysts of the spine. J Neurosurg Spine. 2005;2:372-6. 